\title{
Future Applications of Digital Clothing for Historical Costume: The past, present and future of fashion
}

\author{
Roz McNulty \\ Fashion Innovation Centre \\ 63 Keefer Place \#2605 \\ Vancouver V6B6N6, Canada \\ roz@fashionic.ca
}

\begin{abstract}
What does the future of historical fashion look like with digital reproduction? Clothing Industry 3D Apparel software exists to create 3D clothing renders from 2D patterns. For the industry this allows faster sample, design choices and greater communication with the manufacturers. In this paper I discuss creating historical costume representations in 3D, and evaluate these relative to the possibilities of $2 \mathrm{D}$.
\end{abstract}

Digital fashion. Historical fashion. Pattern design. 3D graphics. Illustration. Mixed reality.

\section{INTRODUCTION}

3D Digital Clothing presentation is evolving within the commercial apparel industry as an alternative to repetitive sampling and communication to buyers and production. There are several software companies that allow you to draft in $2 \mathrm{D}$, sew and mathematically drape cloth over a 3D avatar of personalised body scan.

The biggest difference between illustration (2D) and visualisation (3D) is that illustration (2D) has no data (unless artificially inputted), whilst visualisation (3D) is an amalgamation of data. 3D garments when made is not just an image or an object anymore, it consists of specific pattern pieces (e.g. pockets, collars), specific measurements and shape, top stitches, trims, graphics, colours, and who contributed to which part of the design.

In this paper I will show the potential of what exists for further documenting historical clothing. An introduction of what is possible with examples that myself and others have created with the 3D apparel industry software. We shall see some glimpses into the future of apparel innovation. I want to demonstrate 3D scanning with an iPad, the Occipital camera and Eyexpo software and the occipital camera. I want to show a contrast and an alternative to $3 \mathrm{D}$ illustration and the beginning of mixed realty documentation in the future.

\section{CLOTHING MUSEUMS NOW AND IN THE FUTURE}

Museums are now curating displays that are more interactive. They provide an experience rather than just a show of items. The different ways fashion is displayed in museum settings, and how national and regional identities influence fashion exhibitions. Museums do not have the physical space to display their full collections. Although there is an amazing amount of historical clothing online, it's a $2 \mathrm{~d}$ photograph that you can only enlarge.

\subsection{EXISTING PHYSICAL MUSEUM DISPLAY SPACE}

Dr. Christopher Breward, director of collection and research at the National Galleries of Scotland said at the 2019 FIT symposium:

Less than $3 \%$ of our collection is visible at one
time. $3 \%$ of collection at Museum of Scotland is
visible and $97 \%$ is unseen and heavily booked visible and access.

There is limited display, storage and access at most museums. Online museums can help. But we need to look at $3 \mathrm{D}$ solutions versus $2 \mathrm{D}$ pictures. 


\subsection{EXISTING ONLINE MUSEUMS}

Some museums have online presence. These museums are amazing in that much has been catalogued but they still have you guessing at the true style lines of the garment; beautiful photographs don't tell the whole story.

I enjoy seeing what exists but I also feel that I am still cheated out of how a garment really looks or works. I want to know more. I want to comprehend the construction, the pattern lines and the fabric detail; how that fabric would move.

\section{The Costume Institute at the MET:}

The Costume Institute houses a collection of more than thirty-five thousand costumes and accessories, representing five continents and seven centuries of fashionable dress, regional costumes, and accessories for men, women, and children, from the fifteenth century to the present.

The Museum at the Fashion Institute of Technology (FIT):

The mission of the Museum is to collect, conserve, document, exhibit, and interpret fashion. The Museum's permanent collection encompasses some 50,000 garments and accessories from the 18th century to the present.

\section{National Museum of American History, Clothing} and Accessories:

The Museum cares for one of the nation's foremost collections of men's, women's, and children's garments and accessories-from wedding gowns and military uniforms to Halloween costumes and bathing suits. The more than 30,000 artefacts here represent the changing appearance of Americans from the 1700 s to the present day.

\section{Victoria and Albert Museum:}

The joint collections of Textiles and Dress contain almost 53,090 items and the Fashion collection is currently the largest and most comprehensive collection of dress in the world. It contains links to past exhibits, videos, and articles on major subjects.

The Drexel Digital Museum Project: Historic Costume Collection:

Drexel University's Historic Costume Collection contains more than 7000 items and includes fashion plates, photographs, and 19th- and late20th-century haute couture by French and American designers.

\section{FIT's Online Collection:}

FIT's online collection contains an extensive searchable and browsable gallery. The collection's strength is primarily in modern and contemporary women's fashion.

\section{Kyoto Costume Institute Digital Archive:}

KCl's Digital Archive includes a browsable interface to view costumes by time period from the early 18 th century to the mid-20th century.

\section{Texas Fashion Collection Digital Library:}

The UNT Texas Fashion Collection is dedicated to the preservation and documentation of historically significant fashion, and serves as an educational and inspirational resource for students, researchers, and the general public.

\section{Wayne State University Digital Dress Library:}

Includes the Digital Dress: 200 Years of Urban Style collection. Records are searchable in the database and include examples of occupational, formal, recreational, mourning, masquerade, and everyday wear for men, women, and children. Pieces by European and American designers, local dressmakers and retailers, and home-made garments are included.

\subsection{INTERACTIVE FASHION MUSEUMS}

We Wear Culture:

We Wear Culture was launched by Google in June 2017. It is a collaboration between Google and more than 180 museums, schools, fashion institutions, and other organizations from all parts of the globe. It is part of Google's Arts \& Culture platform, which is digitizing the world's cultural treasures, and functions as a searchable guide to a collective archive of some 30,000 fashion pieces that puts "three millennia of fashion at your fingertips," Google says. It is an amazing and growing collection of essays, immersive 360 experiences, catalogues and links to fashion articles.

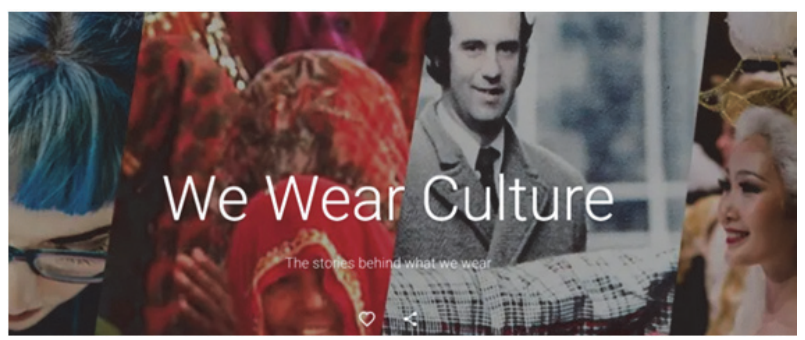

Figure 1: We Wear Culture 
Valentino Garavani Virtual Museum:

Valentino Garavani, legendary fashion designer, has defined a unique world of couture for almost half a century. Over 5000 documents have been installed in a spectacular 3D Palazzo. After downloading the desktop application each visitor can create their unique route through the galleries, to discover and enjoy every aspect of Valentino's extraordinary world.

This museum was created in 2011. At this time I haven't learned a lot about compatibility with the future. It is still an attempt at an interactive navigation of an amazing collection. It is only disappointing that the garments are once again 2D photographs. What does the back of that dress look like?

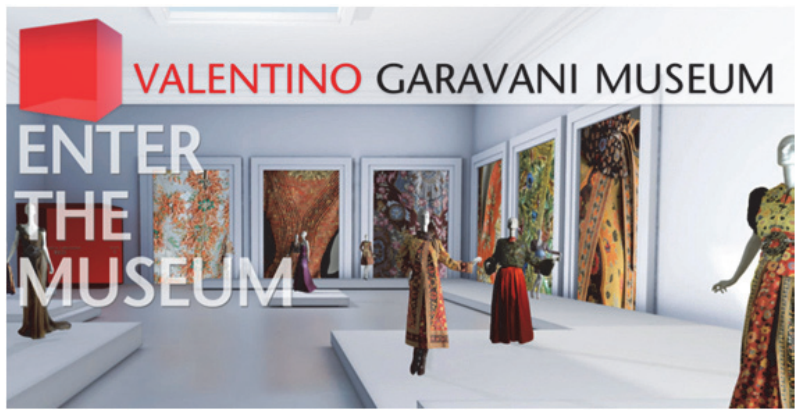

Figure 2: Valentino Garavani Museum.

Christies Virtual Tour: Catherine Deneuve et Yves Saint-Laurent:

Explore timeless classics that define modern French elegance with over 300 YSL designs from Catherine Deneuve's personal collection. This collection was sold in Paris on 24 January 2018.

Once again a 3D navigation of $2 \mathrm{D}$ photos imitating $3 \mathrm{D}$ - but it does show how close it is to happening.

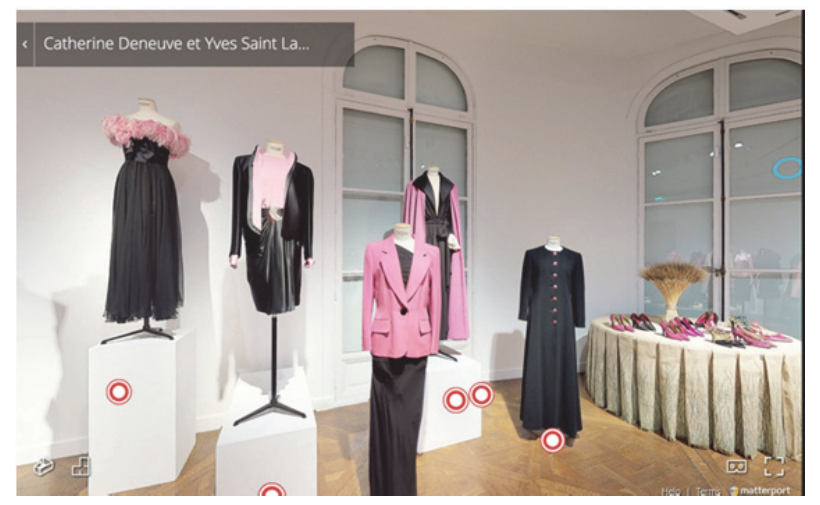

Figure 3: Christies Virtual Tour.

\section{3D SOFTWARE}

\subsection{Existing 3D apparel software}

The following is a list of 3D Digital Clothing Software companies:

- Gerber

- Lectra

- Optitex

- Browzwear

- CLO 3D

Originally created for the math of pattern design, as in scaling or sizing, plus cutting and marker making. All software is now evolving to design firstly. You can draft in 2D, then drape or sew over a 3D avatar even a personalised body scan. One can then start to manipulate design, fabric and drape.

Plus add colour, detail, even embellishment including fur and sequins. It is also possible to then create studio lighting, even animation within the CLO software to imitate movement and show off the drape of the fabric. The CLO 3D software also is a reasonable subscription price of $\$ 500$ US per year and with basic pattern drafting knowledge and basic computer skills you can learn and create.

Because of the easy entry to creation and manipulation, myself and others are starting to create a 1930's pre-war Goetz opera cape trimmed in fur with fabric recreated from the original photograph.

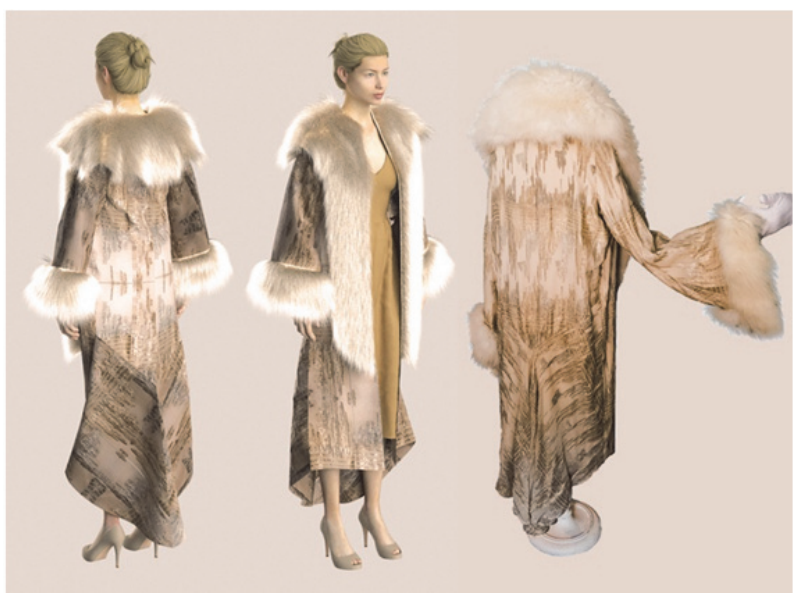

Figure 4: 1930's Goetz opera cape.

Gia Falati created the Balenciaga one seam coat with CLO 3D in her Master thesis. Meanwhile, Sari $\mathrm{Kim}$, an MA student from London College of Fashion, animated a 1913 Talbot Hughes museum piece in CLO 3D. I look forward to recruiting further talent to illustrate the museum of the future. 


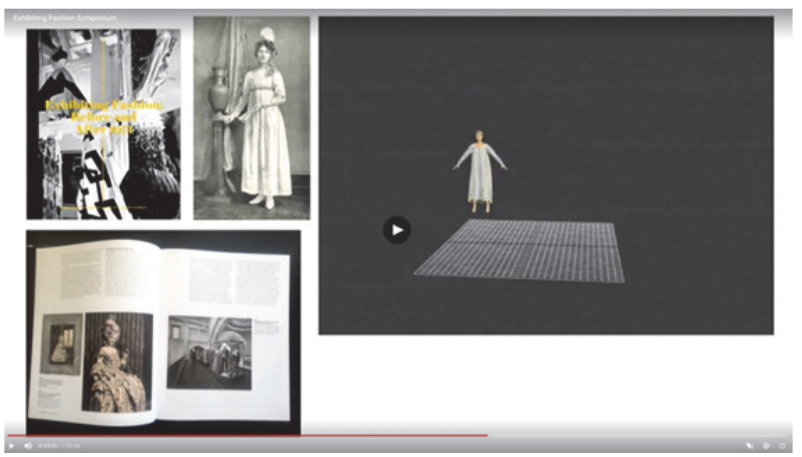

Figure 5: Representing apparel with 3D software.

\subsection{Scanning as an alternative to $3 \mathrm{D}$}

I have been working with the Eyexpo scanner and software for over a year. I have seen it evolve from an engineer's dream to the beta stages of a future software. Eyexpo allows you to scan an object in 3D with just an iPad and an Occipital camera. It takes 5 to 10 minutes and then can be immediately uploaded to a gallery then downloaded in flexible file formats suitable for 3D printing or further rendering in 3D graphics software. Figure 6 shows an example of a 3D scan created using the Eyexpo software.

The difference between 3D scanning and 3D Pattern drafting is that it becomes a $3 D$ surface versus a 3D construction; a visual representation of $3 \mathrm{D}$ versus a flat pattern reconstruction.

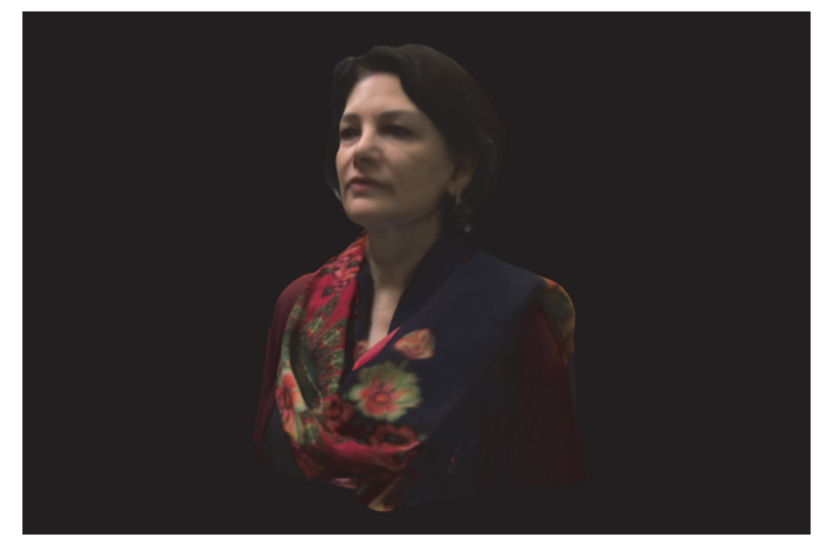

Figure 6: Eyexpo 3D scan of the author - Roz McNulty.

\subsection{Mixed realities and interactive displays}

Both 3D pattern design and 3D scanning can become assets for interactive displays. Recent examples of this are virtual models and avatars (Figure 7).

Another immediate part of the future of display and retail is augmented reality (AR), the ability with code to place a virtual object in your immediate physical space. Examples of this that I have from news and retail are: Ashley James avatar New York Times, Ikea Place and Avametric.

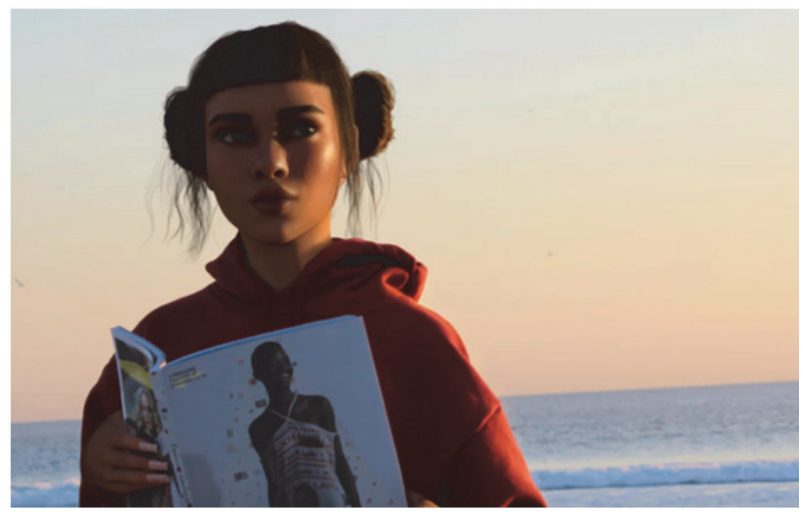

Figure 7: Meet Fashion's First Computer-Generated Influencer'@lilmiquela wears Chanel, Prada and

Supreme, works with fashion magazines and advocates for social change. Does it matter that she is a virtual avatar?

In my EVA London 2019 presentation, I will also discuss backdrop creation for 3D historical clothing displays using a Ricoh Theta 360 Camera.

\section{CONCLUSION}

My overall goal is to clarify what is happening in the 3D apparel design world that I work in as a teacher and designer. I want to show the potential of new technologies to complement our historical clothing collections. My eventual long-term goal is also to get an online 3D museum could evolve with a system of contribution from all the $3 D$ clothing artists around the world.

\section{REFERENCES}

Bain, M. (2017) Google has built a stunning, searchable archive of 3,000 years of world fashion, Quartz. https://qz.com/1002651/google-has-built-a-stunningsearchable-archive-of-3000-years-of-world-fashion/ (retrieved 19 March 2019).

Fibre2Fashion (2019) Interview with Simon Kim, CEO CLO Virtual Fashion.

https://www.fibre2fashion.com/interviews/face2face/clovirtual-fashion/simon-kim/12129-1/?fbclid=IwAR1u7bQFkrHZDWIOIUtnhNipOTIJOp-

twT9tkjs0Miq55tSEHEuQPcvHpO (retrieved 19 March 2019).

Morency, C. (2018) Meet Fashion's First ComputerGenerated Influencer, Business of Fashion. https://www.businessoffashion.com/articles/intelligence/ meeting-fashions-first-computer-generated-influencer-lilmiquela-sousa (retrieved 19 March 2019).

The Museum at FIT (2019) Exhibiting Fashion Symposium.

http://www. fitnyc.edu/museum/events/symposium/exhibiti ng-fashion/index.php (retrieved March 18, 2019).

Valentino Garavani Virtual Museum (2019) http://www.valentinogaravanimuseum.com/\#.UJmJu9uFxh (retrieved 19 March 2019). 